\title{
Longitudinal Residual Stress Analysis in AA2024-T3 Friction Stir Welding
}

\author{
Pierpaolo Carlone* and Gaetano S. Palazzo
}

\author{
Department of Industrial Engineering, University of Salerno, Via Ponte Don Melillo 1, 84084, Fisciano (SA), Italy
}

\begin{abstract}
Friction Stir Welding (FSW) is an innovative solid-state joining process, which is gaining a great deal of attention in several applicative sectors. The opportune definition of process parameters, i.e. minimizing residual stresses, is crucial to improve joint reliability in terms of static and dynamic performance. Longitudinal residual stresses, induced by FSW in AA2024-T3 butt joints, have been inferred by means of a recently developed technique, namely the contour method. Two approaches to stress measurement have been adopted; the former is based on the assumption of uniform material properties, the latter takes into account microstructural effects and material properties variations in the welding zones. The influence of process parameters, namely rotating and welding speeds, on stress distribution is also discussed.
\end{abstract}

Keywords: AA2024-T3, friction stir welding, contour method, residual stress, material properties.

\section{INTRODUCTION}

Medium to high strength aluminum alloys, such as $2 \mathrm{xxx}$, $6 \mathrm{xxx}$, and $7 \mathrm{xxx}$ series, are currently considered of great interest in the transport industries. In particular, the precipitation hardenable AA2024 (Al-Cu) alloy is gaining considerable attention for the realization of barrier beams or fuselage panels. In this context, remarkable research effort is focused on the application of the Friction Stir Welding (FSW) process, as a suitable alternative to fusion welding processes. Indeed, the poor dendritic microstructure and the high porosity in the weld zone, induced using conventional techniques, strongly reduce the mechanical behavior of the assembly. Furthermore, the reduction of production costs and weight and the increase of strength and damage tolerance with respect to riveted lap joints make FSW a very attractive process to the aerospace industry.

FSW is a solid-state welding process, developed and patented by The Welding Institute (TWI) of Cambridge in 1991. Following the early successful applications in aluminum welding, FSW has been applied to other engineering materials, such as copper, steel, titanium, and metal matrix composites. During the process a nonconsumable rotating tool, constituted by a shoulder and a pin, is plunged between the adjoining edges of the parts to be welded and moved along the desired weld line. The combined rotation and translation of the tool locally increase the work piece temperature, due to heat generated by frictional effects and plastic deformation. The induced softening allows the processing material to flow around the pin, from the front (leading edge) to the rear (trailing edge) according to complex patterns, resulting in a solid state weld [1]. Temperature increase and high strain rate deformation lead to the formation of micro-structurally different zones: the nugget or stir zone (NZ) in the center of the weld,

*Address correspondence to this author at the Department of Industrial Engineering, University of Salerno, Via Ponte Don Melillo 1, 84084, Fisciano (SA), Italy; Tel: 0039089 964320; Fax: 0039089 964307;

E-mail: pcarlone@unisa.it surrounded by the thermo-mechanical affected zone (TMAZ) and the heat affected zone (HAZ). Nowadays, a deeper understanding of static strength as well as of fatigue behavior of FSWed assemblies is highly desired for a wider implementation of the technique in safety-critical components. It is commonly accepted that the aforementioned properties mainly rely on residual stresses, microstructure, and microhardness. Even if FSW residual stresses are generally lower if compared to conventional welding processes, an accurate knowledge of their distributions is crucial to numerically investigate buckling behavior [3-5] as well as crack growth and fatigue response [6-13] of welded assemblies. In this sense some results have already been presented in the inherent literature, regarding, for instance, AA5083 [14-16], AA6082 [6,17,18], AA2195 [13], AA2219 [19], and AA2024 [8-12,17,18,20,21] FSW. In more details, Peel et al. investigated the influence of the welding speed on microstructural, microhardness and residual stress on $3 \mathrm{~mm}$ thick AA5083 FSWed butt joints. The stress distribution was inferred by means of synchrotron $\mathrm{X}$-rays, evidencing a tensile status in both the longitudinal and transverse direction. Moreover an increase of the tensile peak was found increasing the welding speed [14]. FSW process was simulated using a fully thermo-mechanical model in [15], declaring good agreement with available results [14]. The influence of dynamical recrystallization effects on residual stress distribution was also suggested. Synchrotron X-ray radiation was employed by Lombard et al. in [16] to analyze $6 \mathrm{~mm}$ thick FSWed plate. The typical residual stresses M-shaped profile was detected, confirming also the dominant role of the welding speed on the tensile peak. Three different aluminum alloys (5754-H111, 2024T3, and 6082-T6) were joined using FSW in [17]. Residual stress measurements were carried on using the slitting (crack compliance) method. Two different inverse methods, namely the linear elastic fracture mechanics (LEFM) and finite element (FE) methods, were implemented, providing similar results. Reported data highlighted the correlation between the stress profile and the microstructural changes in the processing material. The hole drilling technique was applied 
in [18] to measure through the thickness residual stress in four aluminum alloys, namely AA1050-O, AA2024-T4, AA6082-T6, and AA7075-T6, welded according to three different processing conditions. Compressive stresses were found on joint surface in correspondence of the advancing side, replaced by tensile stress inside the joint. An experimental residual stress analysis on $12 \mathrm{~mm}$ thick AA2219-T6 plates, butt joined by FSW, was carried on by $\mathrm{Xu}$ et al. using the hole-drilling strain-gauge method [19]. Different stress profiles were detected at the top and bottom surfaces, following, respectively, a M-shape and a V-shape. Moreover, an increase of the tensile peak was highlighted in defected joints.

As far as AA2024 FSW is regarded, several studies have been focused on the analysis of residual stresses, using numerical and experimental approaches. Two process settings, defined as hot and cold weld, were used by Deplus et al. to weld $2 \mathrm{~mm}$ thick AA2024-T3 plates in the butt joint configuration [17]. Longitudinal stresses were measured using the slitting method, evidencing a more severe residual status assuming cold weld parameters. The adopted method, however, did not allow for the detection of stress variations through the thickness. The same technique was used by Milan et al. to investigate longitudinal and transverse residual stresses in $3.2 \mathrm{~mm}$ thick AA2024-T3 plates [20]. A higher tensile residual stress was measured on the advancing side of the weld and related to the larger heat input, resulting from the higher relative speed between the tool and the material. Sutton et al. measured longitudinal, transverse and normal stresses distributions in $7 \mathrm{~mm}$ thick AA2024 plates in the T3 condition [21], by means of neutron diffraction (ND). The longitudinal stress was found to be the largest tensile component. The analysis was performed assuming one processing condition; the influence of process parameters was not investigated. Despite the relevant data and intriguing conclusions reported in the cited papers, it should be noted that most of the cited works explored very few, if not unique, combinations of process parameters. Moreover, residual stresses were measured in selected locations of the joined plates or considering average values due to intrinsic limits of the employed techniques.

In this paper results provided by an experimental investigation on longitudinal residual stresses in $4 \mathrm{~mm}$ thick AA2024-T3 FSWed butt joints are reported and discussed. The contour method has been applied to map the stresses acting on a section normal to the weld line. The aim of the work is to investigate the influence of process parameters, namely rotating and welding speed, on stress distribution, considering also the influence of microstructural changes on the computed stress field. Two stress maps have been inferred for each test, assuming, respectively, constant material properties and properties variations in the different welding zones (NZ, TMAZ, HAZ). The extension of each zone has been defined by means of a numerical-experimental approach, following experimentally calibrated criteria based on temperature, dynamic viscosity, and grain size values. Local material properties have been quantified using ultrasonic analysis and then employed for stress calculation. The paper is structured as follows: in Section 2 details regarding material, manufacturing process, and analysis procedures are reported, while in Section 3 results are exposed and discussed. Finally, Section 4 deals with relevant findings of the work.

\section{MATERIALS AND METHODS}

\subsection{Material and Welding Process}

In the present investigation, AA2024-T3 aluminum rolled plates (100 mm x $30 \mathrm{~mm} \times 4 \mathrm{~mm})$ were joined by FSW. The nominal composition (wt\%) of the base material is as follows: $3.8-4.9 \mathrm{Cu}, 1.2-1.8 \mathrm{Mg}, 0.3-0.9 \mathrm{Mn}, 0.5 \mathrm{Si}, 0.5 \mathrm{Fe}$, $0.25 \mathrm{Zn}, 0.15 \mathrm{Ti}, 0.1 \mathrm{Cr}$, balance Al. The considered material has been subjected to a solution heat treatment, followed by cold working and natural ageing. Welds have been executed normally to the rolling direction on a MCX 600 ECO machining center. The process set up is shown in Fig. (1).

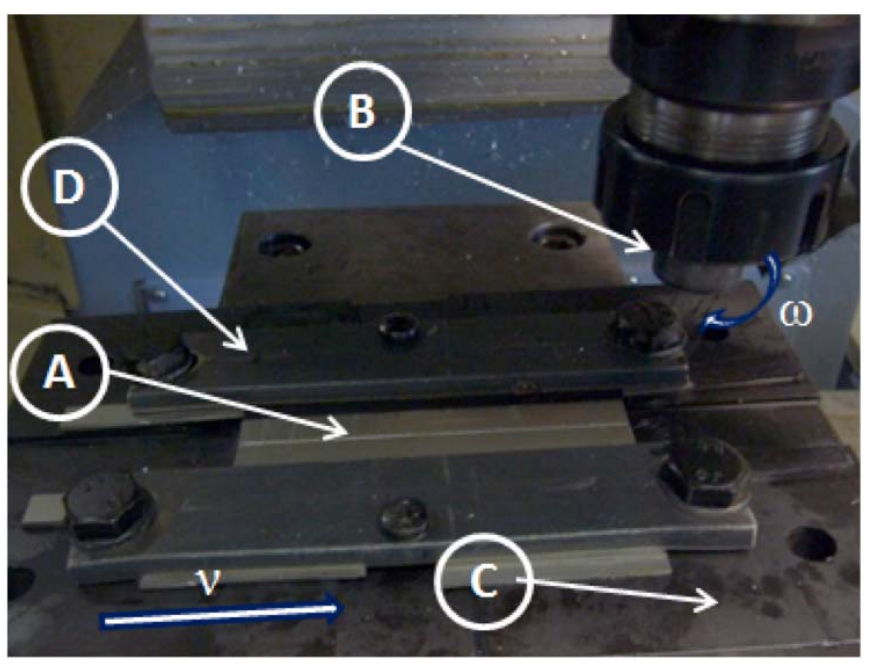

Fig. (1). Friction stir welding process set up (A: plates in reference pocket, B: tool and tool-holder, $\mathbf{C}$ : Inclined base plane imposing the tilt angle, D: clamping system).

A full factorial design of experiments has been adopted, assuming respectively five and three levels for the rotating speed $\omega(800,1000,1200,1400,1600 \mathrm{rpm})$ and feed rate $v$ $(35,70,140 \mathrm{~mm} / \mathrm{min})$. Tilt angle and pin penetration have been defined as $2^{\circ}$ and $0.2 \mathrm{~mm}$, following literature indications. An AISI1040 quenched steel tool (56 HRC) consisted of a $20 \mathrm{~mm}$ diameter shoulder with a conical unthreaded pin has been employed. Pin dimensions are: height $3.80 \mathrm{~mm}$, major diameter $6.20 \mathrm{~mm}$, and cone angle $30^{\circ}$. Preliminary visual inspections and microscopic observations of the joint section showed the presence of internal defects, such as tunnel defect and kissing bonds at rotating speeds lower than $1400 \mathrm{rpm}$, significantly reducing the process window. Taking into account that defect analysis is not the main focus of the present investigation, detailed information are not herein reported. Omitted data, analysis, and related discussions can be found in [22].

\subsection{Welding Zones Identification and Characterization}

In this paragraph, numerical and experimental methods used to individuate the different welding zones (NZ, TMAZ, HAZ) and to evaluate the related properties are reported. As far as AA2024-T3 FSW is concerned, it is relevant to notice that extension, microstructure and mechanical properties of each zone are significantly affected by dynamic recrystallization, dissolution, coarsening, and re-precipitation phenomena, whose kinetics are strongly influenced by 
thermal effects coupled to plastic deformations [23]. Conventional optical metallographic procedures allows for a clear detection of NZ as well as of TMAZ. Indeed, the former is interested by continuous dynamic recrystallization phenomena, resulting in an evident grain refinement with respect to the parent material. In the latter a variable amount of grain distortion, without significant size changes, is generally observed $[2,10,20,22]$. HAZ boundaries are quite difficult to observe using the aforementioned techniques, since no relevant modifications of grain size and shape are induced. However, the temperature field experienced by the processing material during the welding strongly affects precipitates distribution and properties, influencing the microhardness (HV) distribution. As a consequence, the peculiar $\mathrm{HV}$ trend in the HAZ, allows one to indirectly evaluate the HAZ extension [23]. Experimental data have been used to calibrate some criteria, based on temperature, dynamic viscosity, and grain size considerations, implemented in a CFD process model, presented and validated in $[22,24]$, providing an automatic definition of welding zones boundaries.

Taking into account what aforementioned, NZ boundaries have been defined, for each processing conditions, in correspondence of the (numerically computed) onset of recrystallization and grain size change [24]. A criterion based on dynamic viscosity calculation, as reported in $[25,26]$, has been adopted to define TMAZ extension, assuming a reference value of 4E6 Pa.s in correspondence of the separation between TMAZ and HAZ [22]. In Fig. (2) a comparison between the numerically computed and experimentally observed NZ and TMAZ has been reported, showing also a contour of the grain size distribution in the NZ. An indirect definition of HAZ - BM boundaries has been adopted, considering, as generally accepted, that no relevant phenomena take place in the considered material below a threshold temperature [23], herein defined as $250^{\circ} \mathrm{C}$ considering microhardness results presented in [22].

Regarding material characterization, it is relevant to emphasize that the method employed for residual stress evaluation requires elastic properties only. The local elastic modulus has been evaluated by ultrasonic time of flight (TOF) measurements. The used device was a PANAMETRICS 5058PR high voltage pulser-receiver, working in a pulse-echo mode. A V544 ultrasonic probe, generating $10 \mathrm{MHz}$ longitudinal waves, has been used. Other parameters have been defined by trial and error as follows: $100 \Omega$ damping, $200 \mathrm{~V}$ pulse height, $30 \mathrm{~dB}$ attenuation, and $0.1 \mathrm{MHz}$ HP filter. Time of flight measurements have been performed in correspondence of the NZ, TMAZ and HAZ on both sides of the weld. The local elastic modulus has been then inferred according to the following equation:

$$
V_{l}=\sqrt{\frac{E(1-v)}{\rho(1+v)(1-2 v)}}
$$

being $\mathrm{V}_{l}$ the ultrasonic longitudinal speed, $\rho$ the density and $v$ the Poisson ratio. Three measurements have been performed in correspondence of each zone, assuming the average value for the subsequent analysis.

\subsection{Residual Stress Measurement}

\subsubsection{The Contour Method}

The contour method $(\mathrm{CM})$ is a relaxation method allowing one to evaluate the stress distribution on a specimen section [27]. From a theoretical point of view, the contour method is a derivation of the Bueckner's elastic superposition principle, which states that: "if a cracked body subject to external loading or prescribed displacements at the boundary has forces applied to the crack surfaces to close the crack together, these forces must be equivalent to the stress distribution in an uncracked body of the same geometry subject to the same external loading" [28]. In other words stresses to be applied on a specimen section in order to deform the surface to its initial undeformed shape are equivalent to the residual stresses acting on the same section before the cut. Theoretically, all of the three stress components acting on the cut surface can be derived, however, evident limitations in in-plane displacements measurement reduce the effective applicability of CM to normal stresses [27]. The most intriguing capability of the

\section{Advancing Side}

\section{Retreating Side}



Fig. (2). Experimental and numerical NZ and TMAZ (Test 15). Numbers on contour lines indicated the grain size in $\mu \mathrm{m}$. 
method, if compared to other destructive techniques, is that a complete residual stresses mapping can be achieved, following a relatively simple and cheap procedure. Moreover, the experimental steps can be realized using devices and machines currently available in most industrial as well as academic research laboratories. For these reasons, $\mathrm{CM}$ has been widely applied in several contexts, including FSW. Woo et al. in [29] discussed some results provided by an experimental investigation on friction stir processing of AZ31B magnesium alloy. ND and CM were applied for residual stress evaluation providing similar stress distributions. An application of CM to analyse the effect of shot peening and laser shock peening on AA2195 and AA7075 friction stir welds was detailed in [30], highlighting a remarkable through the thickness variation of the longitudinal stress. ND and CM were employed by Prime et al. to investigate longitudinal residual stresses in AA7050T7451 and AA2024-T351 friction stir butt joints [31]. Good agreement was found in stress mapping, evidencing also an M-shaped longitudinal stress profile. More recently, RichterTrummer implemented the CM to analyse the effect of clamping forces in FSW of $3.18 \mathrm{~mm}$ thick AA2198-T851 plates [32]. It was found that higher clamping forces lead to more uniform residual stress distribution through the thickness.

\subsubsection{Sample Cut}

The application of the contour method is based on four consecutive steps: specimen cut, relaxed surface acquisition, data reduction, and stress computation. Specimen sectioning is a crucial step, since it potentially affects the shape of the relaxed surface and, as a consequence, the reliability of the inferred normal stress. The cutting process should respect some prerequisites to avoid or at least reduce measurement errors. The cut should be flat and of high surface finishing, the cut width should be constant and very small and the specimens should be rigidly clamped on both sides. Additionally, the just cut (and relaxed) surfaces should not be re-machined by the cutting tool. The cutting technology more suitable to accomplish this step is the wire electro discharge machining (WEDM). In the present investigation, FSWed specimens have been sectioned in correspondence of the mid-length and orthogonally to the weld line. The WEDM process has been performed by means of a MITSUBISHI FA-20 machine, using a copper $0.25 \mathrm{~mm}$ diameter wire in a deionized water bath. Skim-cut parameters have been used to minimize effects on preexisting stresses.

\subsubsection{Contour Measurement}

After sectioning, residual stresses are free to relax, leading to a three dimensional displacement of the cut surfaces. Two approaches to contour measurement are generally applied, based, respectively, on contact (tactile) or non-contact (optical) techniques. Optical devices are nominally less accurate than tactile machines, such as Coordinates Measuring Machines (CMM), however, the improvement of the acquisition rate and the enlargement of the dataset virtually result in accuracy comparable with tactile systems [33].

In the present analysis, out of plane displacements of the sectioned surfaces have been recorded by means of a CMM
(DEA IMAGE GLOBAL CLIMA), in a moisture and temperature controlled room. The resolution of the used CMM is $0.1 \mu \mathrm{m}$. The machine has been equipped with a contact probe constituted by a $30 \mathrm{~mm}$ height steel stylus and a $3 \mathrm{~mm}$ diameter ruby tip. The machine-probe system has been calibrated before each acquisition, to properly compensate stylus deflection. A $0.5 \mathrm{~mm}$ x $0.5 \mathrm{~mm}$ measurement grid has been programmed in a reference coordinate system associated with the sample, resulting into about 1100 data points for each surface. Taking into account the reduced extension of the cut surface, a hen-peck acquisition mode has been adopted to improve measurement accuracy without excessive penalization of the acquisition time. As aforementioned, the contour method allows for the evaluation of normal stress only: shear stress should be compensated by averaging the opposite displaced contours [27]. To accomplish this prerequisite, cut surfaces on both halves of each specimen have been measured.

\subsubsection{Data Reduction}

This step is relevant for the effectiveness of the whole procedure, since stress computation magnifies measurement errors. What is more, an analytical description of the displaced surface is highly desirable, considering that it allows one to define the FE mesh independently of the measurement grid. Intuitively, nodal displacements can be easily derived if a mathematical representation of the relaxed surface is available. Experimental data have been imported in the MATLAB environment and then averaged and fit to an unique smoothing surface, significantly improving the quality of the regression with respect to the polynomial surface fitting adopted by the same authors in [34]. Finally, nodal displacements from the base plane have been inferred and exported for FE calculations. In Fig. (3a, b) the smoothing surface approximating experimental data and the nodal displacements are shown.

\subsubsection{Stress Computation}

Longitudinal residual stresses distribution has been computed by means of an elastic FE model of the cut sample. The digitalized out of plane displacements have been used, with reversed sign, as input nodal boundary conditions, assuming an initial block shaped geometry. This procedure, commonly adopted for the application of the contour method, is less labor intensive with respect to the creation of the deformed model and the successive forcing of the relaxed surface to a flat status [27-34]. Additional constraints have been imposed on a node on the surface opposed to the displaced section to prevent rigid body motion. The commercial software ANSYS has been used to solve the linear elastic boundary value problem. In Fig. (3c) a computed deformed shape of the half specimen has been depicted. Two stress maps have been inferred for each processing condition. In the first case (LRS1 in what follows) no variation of elastic properties of the processed material is considered, assuming the parent material properties for all the welding zones. In the second set of simulations (LRS2), thermal and mechanical effects in the different welding zones have been considered assigning the ultrasonically detected Young modulus to each zone. As a first approximation, the same set of displacements has been used in both cases. 

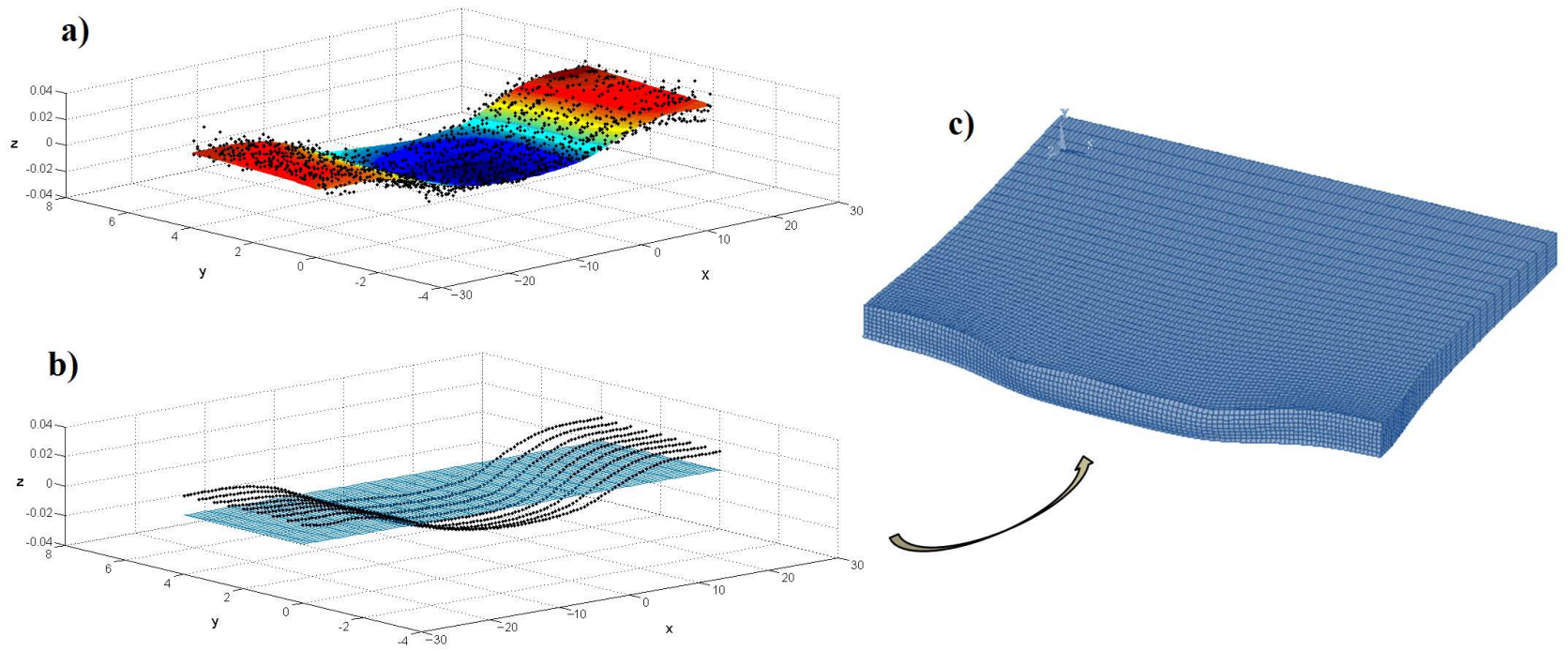

Fig. (3). Experimental points and smoothing surface (a); base plane and nodal displacements (b); deformed shape (Test 12) due to stress relaxation after the cut $(\mathbf{c})$.

\section{RESULTS AND DISCUSSION}

\subsection{Material Characterization and Influence of Properties Variations on Stress Computing}

As aforementioned, during FSW material heating and stirring induce several microstructural phenomena, significantly affecting the final material properties. The base material welded in the present investigation showed the typical rolling microstructure, characterized by elongated grains, whit mean grain size equal to $59.18 \mu \mathrm{m}$. A remarkable grain refinement has been found in the $\mathrm{NZ}$ of all samples, ranging the recrystallized grain size between 8.43 and $11.13 \mu \mathrm{min}$ the central point, respectively in Test 3 and Test 13 [22,24]. No significant grain size variation has been observed in HAZ and TMAZ with respect to the parent material. Ultrasonic measurements showed that, as relatively to the grain size, no significant TOF (and consequently elastic modulus) variations are induced in the HAZ and TMAZ with respect to the base material (see Fig. 4), whose Young modulus resulted equal to $73.3 \mathrm{GPa}$. Slight major, but still not elevated, deviations have been found at the weld line (in correspondence of the NZ) of all samples, being the maximum increase equal to $3.4 \mathrm{GPa}(4.6 \%$ with respect to the parent material modulus) in Test 10 . The positive variation of Young modulus has been related to the grain refinement in the NZ due to continuous dynamic recrystallization. Differently from what already declared relatively to microhardness [22], no evident correlation was found between the Young modulus and process parameters. This aspect can be related to variation of shape and extension of the NZ, as well as the grain size distribution, with process parameters. Considering that ultrasonically measured properties are averaged through the thickness and that at lower $\omega$ the recrystallized zone do not reach the weld root, an increase of the TOF and a reduction of the derived elastic modulus are expected.

In Fig. (5a-d) some results concerning the influence of properties variations on the inferred stress field have been depicted. In particular, Fig. (5a, b) show (in vertical sequence) the LRS distribution computed using uniform material properties, variable material properties, the absolute $\left(\Delta_{\mathrm{LRS}}=\right.$ LRS2-LRS1 $)$ and the percentage difference ( $\Delta_{\text {LRS }} /$ LRS2) 100 relatively to opposite process conditions (Test 1: minimum $\omega$ and $v$; Test 15: maximum $\omega$ and $v$ ). A minimum threshold $( \pm 2 \mathrm{MPa})$ has been adopted for the computation of the LRS percentage difference to avoid calculations in (practically) stress free zone, resulting in the conditioning of the overall evaluation. In Fig. (5c) a summary graph from all test cases, showing the maximum $\Delta_{\text {LRS }}$ and the absolute maximum tensile LRS, has been reported.

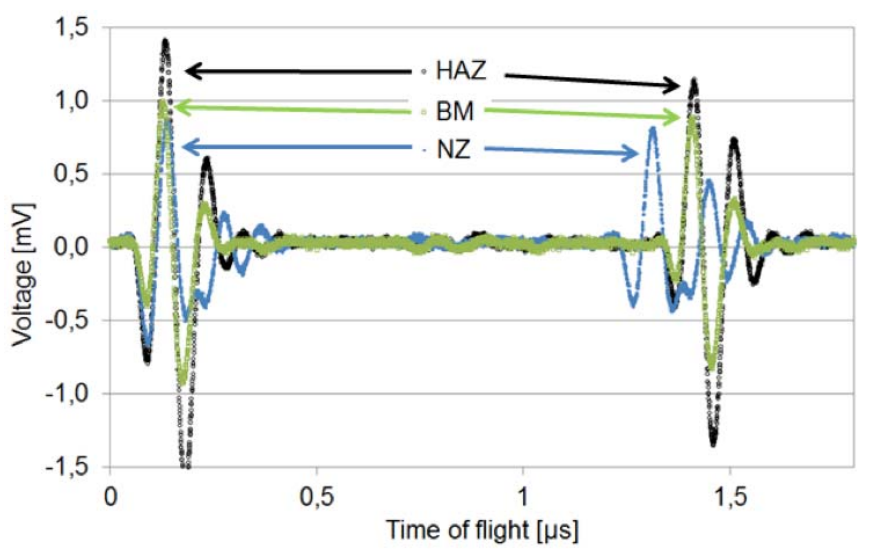

Fig. (4). Ultrasonic signal in the BM, HAZ and NZ (Test 15).

As can be seen, the LRS1 and LRS2 distributions overlap without significant (qualitative as well as quantitative) deviations. Indeed, the maximum stress difference (in absolute value) ranged between about 1 and $4 \mathrm{MPa}$ in all cases, apart Test 3 (7 MPa) and Test 12 (5 Mpa). It should be also noted that the higher differences have been found in correspondence of relatively more stressed zone, resulting in few percentage points of maximum deviations between results provided by the two procedures. The above comparison justifies the widely used assumption of uniform material properties in residual stress evaluation following the 
contour method [28, 30-34], avoiding deeper metallographic and mechanical characterization of the processed material.

However, even focusing on the residual stress field induced by FSW process, it should be noted that the above statement can not be generalized and extended, without further verifications, to more specific cases, i.e. for instance hybrid aluminum-copper, aluminum-steel, or aluminumtitanium FSW. Indeed, obtained outcomes indicate that the maximum difference in LRS corresponds to the maximum Young modulus increase (Test 3 ), implicitly suggesting the need for a preliminary materials characterization for the effective application of the method to hybrid welding processes. What is more, in this case, the equilibrium condition of force and moments acting on the cut section could not be enforced by the equilibrium of displacements and rotations, imposing the implementation of iterative procedures to define the base plane position.

The LRS distribution, as provided by the contour method in Test 6, is shown in Fig. (5d), magnifying the sample thickness for clarity. The depicted stress field is qualitatively representative of LRS maps computed in the whole measurement campaign and evidences a tensile residual stress status in correspondence of the weld line. Two different tensile peaks have been found, localized at a distance from the weld center approximately equal to the shoulder radius into the advancing (AS) and retreating (RS) sides. The largest tensile stress, equal to $145 \mathrm{MPa}$, has been detected in the AS below the top surface, in agreement with other reports $[14,18,19]$, whereas the tensile peak in the RS resulted equal to about $125 \mathrm{MPa}(85 \%$ of the absolute maximum). The typical M-shaped profile has been observed, as already detected by other researchers, testing AA2024 and other aluminum alloys by means of several measurement techniques [11-14,16,17,20,31,32]. The observed asymmetry in the LRS distribution with respect to the weld line can be easily explained considering the different relative (processing material - tool) velocity moving from the AS to the RS. Moreover, line plots (on the right in the same subfigure) of LRS highlight some through the thickness stress variations in correspondence of the tensile peak (AS). As can be seen compressive stresses have been found also in correspondence of the top and bottom surfaces of the welded sample, changing to tensile at a distance from the external surface of about $0.5 \mathrm{~mm}$. A relatively less severe stress profile has been computed at the center of the weld line. The tensile stress in the central region is balanced by compressive residual stresses moving towards the base material, reaching the minimum values about $20 \mathrm{~mm}$ away from the weld line and then slowly approaching (in absolute terms) lower values.
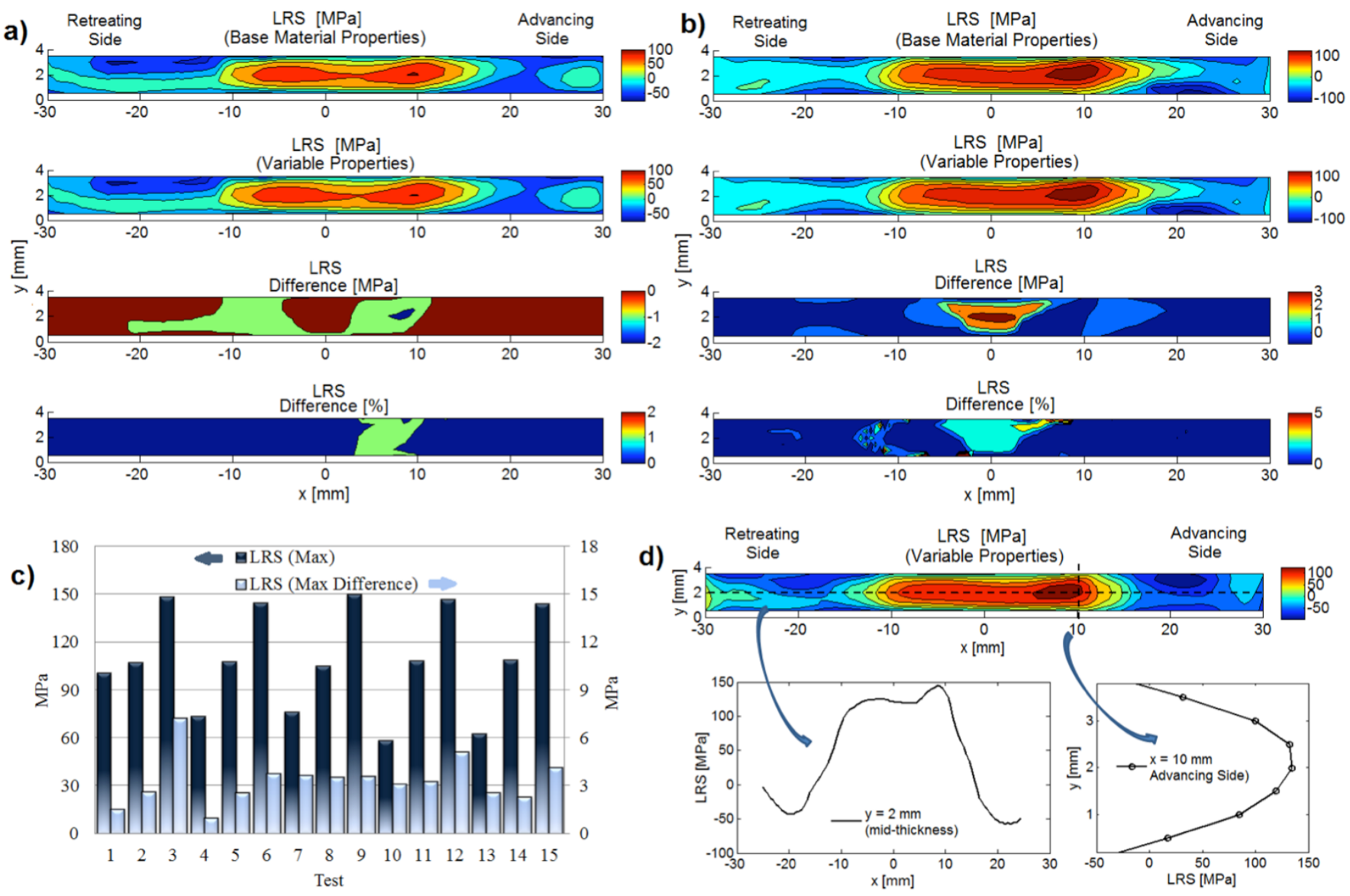

Fig. (5). Longitudinal residual stresses results, as provided by the contour method, assuming uniform material properties and variable material properties (absolute and percentage stress difference are also shown), in correspondence of the two limit test case a) Test $1(\omega=800$ $\mathrm{rpm}-v=35 \mathrm{~mm} / \mathrm{min}$, defected joint); and b) Test $15(\omega=1600 \mathrm{rpm}-v=140 \mathrm{~mm} / \mathrm{min}$, sound joint). c) Bar plot of LRS results from all test cases; d) LRS distributions and profiles at the mid-thickness and across the thickness in the advancing side in Test $6(\omega=1000 \mathrm{rpm}-v=140$ $\mathrm{mm} / \mathrm{min})$. 


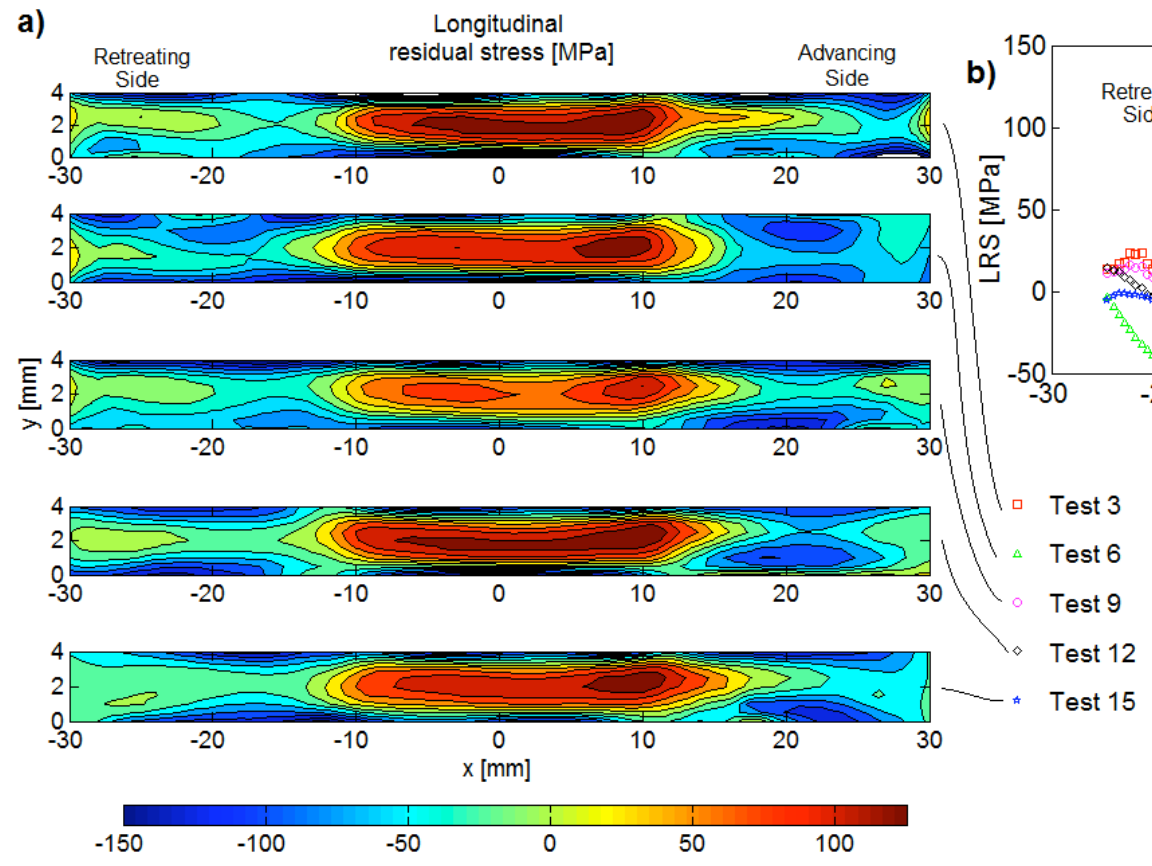

Fig. (6). Influence of rotational speed $\omega$ on LRS: a) stress distribution on the transverse section; b) LRS profiles at the mid-thickness; c) LRS profiles across the thickness in the advancing side ( $v=140 \mathrm{~mm} / \mathrm{min}$ in all test cases $)$.

\subsection{Influence of Process Parameters on LRS}

Figs. $(6,7)$ graphically outline the influence of process parameters $\omega$ and $v$ on LRS. Again, the reported distributions and profiles fairly agree with results presented in the herein cited bibliography, evidencing two peaks in the tensile stressed zone and the presence of compression on both sides of the weld line. Furthermore, a stress reduction is observed at the center of the section $(x=0)$, preserving, in all the examined cases, the positive sign. The absolute maximum is always localized in the AS at a distance from the weld line approximately equal to the shoulder radius, i.e. at higher relative velocity and shear strain rate. The value of the tensile peak in the RS lied in a range whose lower limit was about the $80 \%$ of the peak value in the advancing side. In particular, the gap between tensile peaks appears more evident at lower $\omega$, i.e. when the difference in material - tool relative motion between the AS and the RS is higher.

Obtained outcomes, in terms of stress profiles and tensile peaks, suggest a key role played by $v$. As depicted in Fig. $(\mathbf{6 b}, \mathbf{c})$, a fair superimposition of stress profiles can be observed varying $\omega$ in the considered range and assuming $v$ as fixed. On the other hand, the increase of $v$ induces relatively more severe residual stress status, as highlighted also in Fig. (7a-c). The predominant role of $v$ can be justified keeping in mind that it directly establishes the thermal cycle in terms of heating and cooling rates. Indeed, for a fixed value of $\omega$, similar temperature peaks are experienced by the processing material despite consistent $v$ variations [22]. The increase of $v$ reduces the time available for the diffusion of the heat dissipated in the material away from the weld line. As a consequence, higher temperature gradients are induced and higher stresses on cooling should be expected. Inferred distributions evidenced also the influence of the presence of welding defects on LRS. In defected joints, at lower $v$ (Tests 1,4 , and 7), a remarkable increase of the tensile stress peak with respect to sound joints processed using the same $v$ (Tests 10 and 13) has been detected, in agreement with other reports [19]. This effect vanishes at higher $v$.

The influence of $v$ on the tensile peak has been also tested by means of simple regression analysis. In particular linear and logarithmic regressions have been performed considering the whole dataset $(\mathrm{A})$ and reducing the dataset to sound joints (B). A remarkable correlation coefficient $\mathrm{R}^{2}$ has been obtained in all conditions, as summarized in Table 1 .

On the other hand, a very low correlation coefficient has been found repeating the procedure assuming $\omega$ as independent variable. It should be remarked, however, that the reduced extension of the dataset, in particular in Case B, did not allow for a rigorous statistical analysis, therefore the aforementioned considerations should be considered as indicative of the key role played by $v$. It is worth also noting that the relatively better correlation adopting a logarithmic regression indicates the probable approaching of a tensile peak limit as $\omega$ increases, in agreement with the temperature peak trend described in [22].

\section{CONCLUSIONS}

The longitudinal residual stress distribution in AA2024T3 friction stir welded butt joints has been investigated by means of the contour method. Two approaches to stress computation have been adopted, assuming, respectively, uniform and variable material properties. Taking into account what above reported, the following conclusions can be highlighted:

i. an increase of the Young modulus is induced by the grain refinement in the NZ, however, no evident correlation with process parameters has been observed. Negligible elastic modulus variations have 

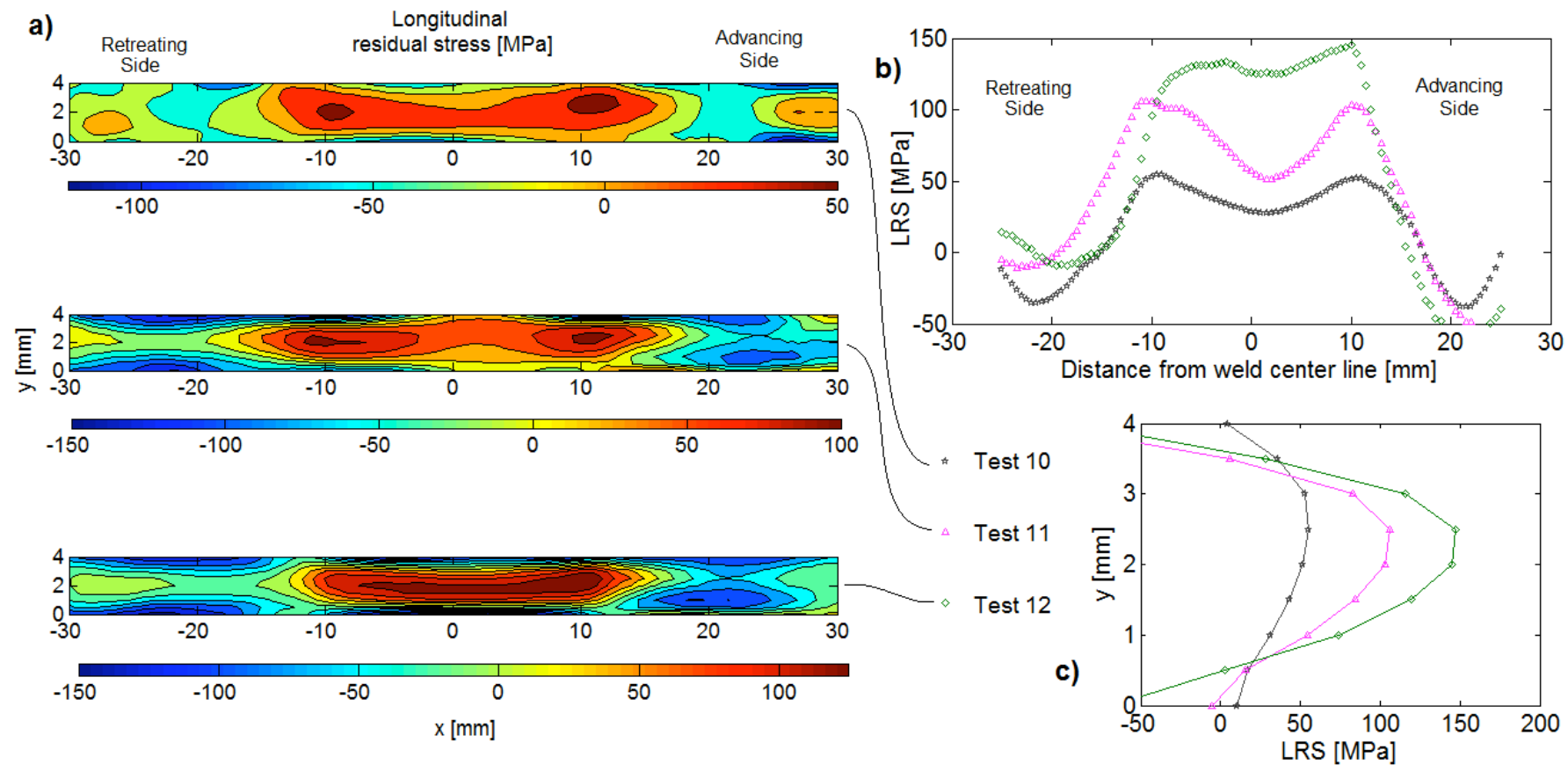

Fig. (7). Influence of welding speed $v$ on LRS: a) stress distribution on the transverse section; b) LRS profiles at the mid-thickness; c) LRS profiles across the thickness in the advancing side $(\omega=1400 \mathrm{rpm}$ in all test cases).

been found in the HAZ and TMAZ with respect to the parent material;

ii. a detailed mapping of longitudinal residual stresses has been achieved by means of the used procedure, providing suitable material to validate computational simulative models of the process and to be included in static as well as dynamic analysis of welded assemblies;

iii. the assumption of uniform material properties appears acceptable in the investigated case, but not generalizable. Further development of the method are needed in order to investigate more complex cases, such as hybrid FSW;

iv. an asymmetric longitudinal residual stress distribution has been found for all processing conditions, characterized by a tensile stress in correspondence of the weld line, balanced by compressive residual stresses moving toward the base material. Two tensile peaks, describing the typical $\mathrm{M}$ shaped stress profile, have been measured in the tensile region, being the minor peak (in the RS) at least the $80 \%$ of the absolute maximum (in the AS);

v. the welding speed resulted the dominant process parameter relatively to process induced longitudinal residual stresses, since it directly affects heating and cooling cycles. The increase of $v$ reduces the time available for heat diffusion away from the weld line, inducing higher temperature gradients and higher stresses on cooling. A minor influence of the rotating speed has been observed.

\section{CONFLICT OF INTEREST}

The authors confirm that this article content has no conflict of interest.
Table 1. Regression Analysis Results

\begin{tabular}{|c|c|c|c|}
\hline Dataset & Regression Type & Equation & $\mathbf{R}^{2}$ \\
\hline \hline \multirow{2}{*}{ A } & linear & $0.672 v+54.64$ & 0.90 \\
\cline { 2 - 4 } & logarithmic & $52.34 \ln (v)-112.77$ & 0.92 \\
\hline \multirow{2}{*}{ B } & linear & $0.771 v+41.93$ & 0.93 \\
\cline { 2 - 4 } & logarithmic & $61.44 \ln (v)-156.15$ & 0.99 \\
\hline
\end{tabular}

\section{ACKNOWLEDGEMENTS}

Declared none.

\section{REFERENCES}

[1] H.N.B. Schmidt, T.L. Dickerson, and J.H. Hattel, "Material flow in butt friction stir welds in AA2024-T3", Acta Mater., vol. 54, pp. 1199-1209, February 2006.

[2] M.A. Sutton, B. Yang, A.P. Reynolds, and R. Taylor, "Microstructural studies of friction stir welds in 2024-T3 aluminum", Mater. Sci. Eng. A Struct., vol. 323, pp. 160-166, January 2002.

[3] J.W. Yoon, G.H. Bray, R.A.F. Valente, and T.E.R. Childs, "Buckling analysis for an integrally stiffened panel structure with a friction stir weld", Thin Wall. Struct., vol. 47, pp. 1608-1622, December 2009.

[4] R.M.F. Paulo, P. Carlone, R.A.F. Valente, F. Teixeira-Dias, and G.S. Palazzo, "Integrated design and numerical simulation of stiffened panels including friction stir welding effects", Key. Eng. Mater., vol. 554-557, pp. 2237-2242, April 2013

[5] R.M.F. Paulo, F. Teixeira-Dias, and R.A.F. Valente, "Numerical simulation of aluminium stiffened panels subjected to axial compression: Sensitivity analyses to initial geometrical imperfections and material properties", Thin Wall Struct., vol. 62, pp. 65-74, January 2013.

[6] P.M.G.P. Moreira, A.M.P. de Jesus, A.S. Ribeiro, and P.M.S.T. de Castro, "Fatigue crack growth in friction stir welds of 6082-T6 and 6061-T6 aluminium alloys: A comparison", Theor. Appl. Fract. Mech., vol. 50, pp. 81-91, October 2008. 
[7] P.M.G.P. Moreira, F.M.F. de Oliveira, and P.M.S.T. de Castro, "Fatigue behaviour of notched specimens of friction stir welded aluminium alloy 6063-T6", J. Mater. Process. Technol., vol. 207, pp. 283-292, October 2008.

[8] G. Bussu and and P.E. Irving, "The role of residual stress and heat affected zone properties on fatigue crack propagation in friction stir welded 2024-T351 aluminium joints", Int. J. Fatigue, vol. 25, pp. 77-88, January 2003.

[9] R. Citarella, P. Carlone, M. Lepore, and G.S. Palazzo, "A FEMDBEM investigation of the influence of process parameters on crack growth in aluminum friction stir welded butt joints", Key. Eng. Mater., vol. 554-557, pp. 2118-2126, April 2013.

[10] A. Ali, X. An, C.A. Rodopoulos, M. W. Brown, P. O'Hara, A. Levers, and S. Gardiner, "The effect of controlled shot peening on the fatigue behavior of 2024-T3 aluminium friction stir welds", Int. J. Fatigue, vol. 29, pp.1531-1545, August 2007.

[11] A.F. Golestaneh, Aidy Ali, and M. Zadeh, "Modelling the fatigue crack growth in friction stir welded joint of 2024-T351 Al alloy", Mater. Des., vol. 30, pp. 2928-2937, September 2009.

[12] L. Fratini, S. Pasta, and A.P. Reynolds, "Fatigue crack growth in 2024-T351 friction stir welded joints: Longitudinal residual stress and microstructural effects", Int. J. Fatigue, vol. 31, pp. 495-500, March 2009.

[13] O. Hatamleh, "A comprehensive investigation on the effects of laser and shot peening on fatigue crack growth in friction stir welded AA 2195 joints", Int. J. Fatigue, vol. 31, pp. 974-988, May 2009.

[14] M. Peel, A. Steuwer, M. Preuss, and P.J. Withers, "Microstructure, mechanical properties and residual stresses as a function of welding speed in aluminium AA5083 friction stir welds", Acta Mater., vol. 51, pp. 4791-4801, September 2003.

[15] M. Grujicic, G. Arakere, H.V. Yalavarthy, T. He, C.-F. Yen, and B.A. Cheeseman, "Modeling of AA5083 material-microstructure evolution during butt friction-stir welding", J. Mater. Eng. Perform., vol. 19, pp.672-684, July 2010.

[16] H. Lombard, D.G. Hattingh, A. Steuwer, and M.N. James, "Effect of process parameters on the residual stresses in AA5083-H321 friction stir welds", Mater. Sci. Eng. A Struct., vol. 501, pp. 119124, February 2009.

[17] K. Deplus, A. Simar, W. Van Haver, and B. de Meester, "Residual stresses in aluminium alloy friction stir welds", Int. J. Adv. Manuf. Technol., vol. 56, pp. 493-504, September 2011.

[18] L. Fratini, and B. Zuccarello, "An analysis of through-thickness residual stresses in aluminium FSW butt joints", Int. J. Mach. Tool. Manuf., vol. 46, pp. 611-619, May 2006.

[19] W. Xu, J. Liu, and H. Zhu, "Analysis of residual stresses in thick aluminum friction stir welded butt joints", Mater. Des., vol. 32, pp. 2000-2005, April 2011.

[20] M.T. Milan, W.W. Bose Filho, J.R. Tarpani, A.M.S. Malafaia, C.P.O. Silva, B.C. Pellizer, and L.E. Pereira, "Residual stress evaluation of AA2024-T3 friction stir welded joints", J. Mater. Eng. Perform., vol. 16, pp. 86-92, February 2007.

[21] M.A. Sutton, A.P. Reynolds, D.-Q. Wang, and C.R. Hubbard, "A study of residual stresses and microstructure in 2024-T3 Aluminum friction stir butt welds", J. Eng. Mater.-T.ASME, vol. 124, pp. 215221, April 2002.

[22] P. Carlone and G.S. Palazzo, "Influence of process parameters on microstructure and mechanical properties in AA2024-T3 friction stir welding”, Metallogr. Microstruct. Anal., DOI 10.1007/s13632013-0078-4, 2013.

[23] C. Genevois, D. Fabrègue, A. Deschamps, and W.J. Poole, "On the coupling between precipitation and plastic deformation in relation with friction stir welding of AA2024 T3 aluminium alloy", Mater. Sci. Eng. A Struct., vol. 441, pp. 39-48, December 2006.

[24] P. Carlone and G.S. Palazzo, "A numerical and experimental analysis of microstructural aspects in AA2024-T3 friction stir welding”, Key. Eng. Mater., vol. 554-557, pp. 1022-1030, April 2013.

[25] H. Atharifar, D. Lin, and R. Kovacevic, "Numerical and experimental investigations on the loads carried by the tool during friction stir welding", J. Mater. Eng. Perform., vol. 18, pp. 339350, June 2009.

[26] R. Nandan, G.G. Roy, and T. Debroy, "Numerical Simulation of Three-Dimensional Heat Transfer and Plastic Flow During Friction Stir Welding", Metall. Mater. Trans. A, vol. 37, pp. 1247-1259, April 2006.

[27] M.B. Prime, "Cross-sectional mapping of residual stresses by measuring the surface contour after a cut", J. Eng. Mater.-T.ASME, vol. 123, pp.162-168, April 2001.

[28] H.F Bueckner., "The propagation of cracks and the energy of elastic deformations", Trans. A.S.M.E., vol. 80, pp. 1225-1230, August 1958.

[29] W. Woo, H. Choo, M.B. Prime, Z. Feng, and B. Clausen, "Microstructure, texture and residual stress in a friction-stirprocessed AZ31B magnesium alloy", Acta Mater., vol. 56, pp. 1701-1711, May 2008

[30] O. Hatamleh and A. DeWald, "An investigation of the peening effects on the residual stresses in friction stir welded 2195 and 7075 aluminum alloy joints", J. Mater. Process. Technol., vol. 209, pp. 4822-4829, June 2009.

[31] M.B. Prime, T. Gnäupel-Herold, J.A. Baumann, R.J. Lederich, D.M. Bowden, and R.J. Sebring, "Residual stress measurements in a thick, dissimilar aluminum alloy friction stir weld", Acta Mater., vol. 54, pp. 4013-4021, September 2006.

[32] V. Richter-Trummer, E. Suzano, M. Beltrão, A. Roos, J.F. dos Santos, and P.M.S.T. de Castro, Influence of the FSW clamping force on the final distortion and residual stress field, Mater. Sci. Eng. A Struct., vol. 538, pp. 81- 88, March 2012.

[33] M.B. Prime, R. J. Sebring, J. M. Edwards, D. J. Hughes, and P. J. Webster, "Laser surface-contouring and spline data-smoothing for residual stress measurement", Exp. Mech., vol. 44, pp.176-184, April2004.

[34] P. Carlone and G.S. Palazzo, "Experimental analysis of the influence of the process parameters on residual stress in AA2024T3 friction stir welds", Key. Eng. Mater., vol. 504-506, pp. 753758, February 2012.

(c) Carlone and Palazzo; Licensee Bentham Open.

This is an open access article licensed under the terms of the Creative Commons Attribution Non-Commercial License (http://creativecommons.org/licenses/by-nc/3.0/) which permits unrestricted, non-commercial use, distribution and reproduction in any medium, provided the work is properly cited. 